\title{
Faktor yang Berhubungan dengan Nyeri Dismenore Primer pada Siswi di SMA Negeri 15 Semarang
}

\author{
Wahidah Rohmawati ${ }^{*}$, Dyah Ayu Wulandari ${ }^{2}$ \\ ${ }^{1}$ Prodi Magister Kesehatan Masyarakat, Jurusan Pascasarjana,Universitas Negeri Semarang \\ 2Prodi DIV Bidan Pendidik, Jurusan Kebidanan, Stikes Karya Husada Semarang \\ *Email korespondensi: wahidahrohmawati1@gmail.com
}

Article Info

Article history:

Submitted: 2019-06-26

Accepted: 2019-08-03

Published: 2019-08-31

Keywords:

Menarche; sports; stress; primary dysmenorrheal pain;

\section{ABSTRACT}

The result of interview with 10 students found that they have ever experienced (dysmenorrheal) they did not focus on teaching and learning until they asleep in the classroom, and asked to permission to went home because unable to bear the pain that they feel, one of them rarely did physical activity such as sports, then they feel (dysmenorrheal) when menstrual, they also were burdened by tasks and rountines of study, if they did examination. The purpose of this study was: to analyze the factors of primary dysmenorrheal on students at SMA Negeri 15 Semarang. This research was quantitative and it used cross- sectional method, the samples of this study were 138 respondents, and the researcher used proportionate stratified random sampling. The researcher also used chi-square test. The result of this study: it is shown that there was correlation between menarche with primary dysmenorrheal with evidence $p$-value $<0,001$, there were correlation between routinely of sport with primary dysmenorrheal with evidence $p$-value $<0,001$, there were correlation between stress with primary dysmenorrheal with evidence $p$-value $<0,001$. Recommendation: the teenagers are expected to increase sports activity and avoid stress so that can reduce the pain of dysmenorrheal.

\section{ABSTRAK}

Kata Kunci:

Menarche;

Olahraga; Stres;

Nyeri Dismenore

Primer;

\begin{abstract}
Hasil wawancara dengan 10 orang siswi didapatkan bahwa mereka pernah mengalami nyeri haid (dismenore), mereka tidak berkonsentrasi dalam proses belajar-mengajar sampai tertidur didalam kelas bahkan sampai meminta izin untuk pulang karena tidak tahan dengan nyeri yang dialami, diantara mereka jarang melakukan aktivitas fisik seperti olahraga, sehingga mereka mengalami nyeri haid (dismenorea) pada saat menstruasi, mereka juga terbebani dengan tugas dan rutinitas belajar terlebih jika menghadapi ujian. Tujuan penelitian: Menganalisis faktor yang berhubungan dengan Dismenore primer pada siswi di SMA Negeri 15 Semarang. Jenis penelitian kuantitatif, desain penelitian cross sectional, populasi penelitian yaitu siswi kelas X, sebanyak 211 orang dan jumlah sampel 138 responden, tehnik sampling Proportionate Stratified Random Sampling. Uji hubungan antara variabel menggunakan uji chi-square. Hasil Penelitian: menunjukkan ada hubungan antara menarche dengan dismenore primer nilai $\mathrm{p}<0,001$, ada hubungan antara kebiasaan olahraga dengan dismenore dengan nilai $p<0,001$, ada hubungan antara stres dengan dismenore dengan nilai $p<0,001$. Saran: Para remaja diharapkan untuk meningkatkan aktifitas olahraga, dan menghidari stres sehingga dapat meminimalisir/mengurangi nyeri dismenore.
\end{abstract}




\section{PENDAHULUAN}

Data dari World Health Organization (WHO) didapatkan kejadian sebesar 1.769.425 jiwa (90\%) wanita yang mengalami dismenore. Rata-rata di negara Eropa dismenore terjadi pada $45-97 \%$ wanita. Dengan prevalensi terendah di Bulgaria $(8,8 \%)$ dan tertinggi mencapai $94 \%$ di negara Finlandia.Nyeri haid terjadi pada lebih dari setengah wanita usia reproduksi dengan prevalensi yang beragam. ${ }^{1,2}$ Prevalensi dismenore primer di Indonesia cukup tinggi yaitu 60-75\% pada perempuan muda. Menurut Santoso, prevalensi dismenore di Indonesia $64,25 \%$ yang terdiri dari 54,89\% dismenore primer dan $9,36 \%$ dismenore sekunder. ${ }^{3}$

Penyebab dismenore primer sampai saat ini masih belum jelas, tetapi beberapa teori menyebutkan bahwa dismenore dapat terjadi karena adanya peningkatan produksi prostaglandin. Dismenore primer dimulai dalam 6 hingga 12 bulan setelah menarche. Menarche pada remaja putri sangat bervariasi, yaitu antara usia 10-16 tahun, tetapi umumnya terjadi pada usia $11-12$ tahun. ${ }^{4}$

Berbagai penelitian telah dilakukan untuk mengidentifikasi faktor resiko yang terkait dengan kejadian dismenore primer. Faktor resiko ialah kurang melakukan aktivitas fisik. Kurangnya aktivitas selama menstruasi dan kurangnya olah raga dapat menyebabkan sirkulasi darah dan oksigen menurun. Aliran darah dan sirkulasi oksigen yang kurang dalam uterus dapat menimbulkan nyeri. Selain dari kedua faktor tersebut diatas, stress juga merupakan faktor resiko kejadian dismenore primer. Stres memicu perubahan hormonal pada hipotalamik pituitari ovarium (HPO) yang berdampak tergangunya hormon ovarium sehingga rentan mengalami masalah pada saat menstruasi. Permasalah stres pada remaja diakibatkan berbagai hal diantaranya karena stres pada saat belajar, susah tidur, kegiatan sekolah yang padat bahakan permaasalahn keluarga. Stres pada remaja juga dipicu adanya persaingan antara teman bermain. ${ }^{5-7}$

Salah satu cara yang sangat efektif untuk mencegah dismenore ini adalah melakukan aktivitas olahraga. Olahraga secara teratur seperti berjalan kaki, jogging, berlari, bersepeda, renang, atau senam aerobik dapat memperbaiki kesehatan secara umum dan membantu menjaga siklus menstruasi agar teratur. Hal ini didukung oleh hasil penelitian yang dilakukan oleh Daley yang menyatakan exercise efektif untuk menurunkan dismenore primer. ${ }^{8,9}$

Diana Sari (2013) menunjukan adanya hubungan antara stres dengan kejadian dismenore primer pada Mahasiswi Pendidikan Dokter Fakultas Kedokteran Universitas Andala. Penelitian Dewi (2011) menjukan adanya pengaruh dismenore terhadap penurunan aktifitas siswi SMK Batik 1 Surakarta. ${ }^{10,11}$

Hasil wawancara dengan 10 orang siswi didapatkan bahwa mereka pernah mengalami nyeri haid (dismenore), mereka tidak berkonsentrasi dalam proses belajarmengajar sampai tertidur didalam kelas bahkan sampai meminta izin untuk pulang karena tidak tahan dengan nyeri yang dialami. Diantara mereka mengatasinya dengan minum air putih, menggosokan minyak angin bahkan kebanyakan dari mereka hanya duduk didalam kelas, mereka beranggapan bahwa nyeri tersebut tidak perlu ditangani mereka mengatakan masih normal. Hanya seorang dari mereka yang mengunjungi UKS, karena nyeri yang dialami tidak bisa ditahan lagi. Disamping itu didapatakan 
informasi, diantara mereka jarang melakukan aktivitas fisik seperti olahraga, sehingga mereka mengalami nyeri haid (dismenorea) pada saat menstruasi, mereka juga mengatakan terbebani dengan tugas dan rutinitas belajar terlebih jika menghadapi ujian. Sehingga merasa cemas dan tegang, dimana kondisi ini menimbulkan nyeri haid (dismenorea). Tujuan penelitian untuk menganalisis faktor-faktor yang berhubungan dengan nyeri Dismenore primer pada siswi di SMA Negeri 15 Semarang.

\section{METODE PENELITIAN}

Jenis penelitian kuantitatif dengan desain penelitian cross sectional, populasi dalam penelitian ini siswi kelas $X(X 1-X 10)$ sebanyak 211 orang dan jumlah sampel 138 responden dengan perhitungan menggunakan rumus slovin, tehnik sampling Proportionate Stratified Random Sampling, data diolah dengan bantuan aplikasi komputer, analisis data dengan uji hubungan antara variabel menggunakan uji chisquare.Variabel dalam penelitian ini terdiri dari variabel dependen yaitu dan nyeri dismenore primer dan variabel independen yaitu menarche, kebiasaan olahraga, stress. Nyeri dismenore diukur menggunakan kuesioner yang berisikan pertanyan tentang nyeri yang dialami.

\section{HASIL PENELITIAN}

Setelah data penelitian dianalisis maka diperoleh hasil sebagai berikut:

Tabel 1: Distribusi frekuensi variabel penelitian faktor yang berhubungan dengan nyeri dismenore primer pada siswi di SMA Negeri 15 Semarang

\begin{tabular}{lcc}
\hline \multicolumn{1}{c}{ Variabel } & Frekuensi & Presentase (\%) \\
\hline Menarche & 34 & 24.6 \\
$<12$ Tahun & 104 & 75,4 \\
>12 Tahun-16 Tahun & & \\
Kebiasaan Olahraga & 0 & 0,0 \\
Tidak berolahraga & 91 & 65,9 \\
Olahraga ringan (<3 x seminggu) & 44 & 31,9 \\
Olahraga sedang (1-3 x seminggu) & 3 & 2,2 \\
Olahraga berat (6 x seminggu) & & 17,4 \\
Stres & 24 & 25,4 \\
Normal & 35 & 34,8 \\
Stres ringan & 48 & 9,4 \\
Stres sedang & 13 & 13,0 \\
Stres berat & 18 & 17,4 \\
Stres sangat berat & & 45,7 \\
Dismenore Primer & 24 & 23,9 \\
Tidak dismenore & 63 & 13,0 \\
Nyeri ringan & 33 & \\
Nyeri sedang & 18 & \\
Nyeri berat & &
\end{tabular}

Sumber: Data primer, 20

Berdasarkan tabel 1. Dapat diketahui bahwa dari 138 responden, lebih banyak mendapatkan menarche pada usia $>12$ tahun-16 tahun yaitu 104 resonden $(75,4 \%)$, sedangkan pada usia $<12$ tahun yaitu 34 responden (24,6\%). Variabel kebiasan olahraga dari 138 responden, lebih banyak responden yang memiliki kebiasaan 
olahraga ringan yaitu 91 responden (65,9\%), 44 responden (31,9\%) memiliki kebiasaan olahraga sedang, paling sedikit yaitu 3 responden (2,2\%) memiliki kebiasaan olahraga berat dan tidak ada responden yang tidak berolahraga. Variabel stres sebagian besar responden mengalami stres sedang yaitu 48 responden $(34,8 \%)$, 35 reponden $(25,4 \%)$ mengalami stres ringan, 24 responden $(17,4 \%)$ tidak mengalami stres/normal, 18 responden (13,0\%) mengalami stres sangat berat dan paling sedikit yaitu 13 responden $(9,4 \%)$ mengalami stres berat. Variabel dismenoree primeer sebagian besar responden mengalami dismenore primer dengan nyeri ringan yaitu 63 responden (45,7\%), 33 reponden $(23,9 \%)$ mengalami nyeri sedang, 24 responden $(17,4 \%)$ tidak mengalami dismenore dan 18 responden $(13,0 \%)$ yang mengalami dismenore dengan nyeri berat.

Tabel 2: HubunganMenarche dengan nyeri Dismenore primer pada siswi di SMAN15 Semarang

\begin{tabular}{|c|c|c|c|c|c|c|}
\hline \multirow[t]{2}{*}{ Menarche } & \multicolumn{4}{|c|}{ Dismenore primer } & \multirow[t]{2}{*}{ Jumlah \% } & \multirow{2}{*}{$\begin{array}{l}\rho- \\
\text { value }\end{array}$} \\
\hline & Tidak & $\begin{array}{l}\text { Nyeri } \\
\text { ringan }\end{array}$ & $\begin{array}{l}\text { Nyeri } \\
\text { sedang }\end{array}$ & Nyeri berat & & \\
\hline$<12$ tahun & $3(2.2 \%)$ & $8(5.8 \%)$ & $(8.0 \%)$ & $12 \quad(8.7 \%)$ & $34(24,6 \%)$ & $<0.001$ \\
\hline$>12$ tahun -16 tahun & $21(15,2 \%)$ & $55(39,9 \%)$ & $22(15,9 \%)$ & $6(4,3 \%)$ & $104(75,4 \%)$ & \\
\hline Total & $24(17,4 \%)$ & $63(45,7 \%)$ & $33 \quad(23,9 \%)$ & $18(13,0 \%)$ & $138(100 \%)$ & \\
\hline
\end{tabular}

Hasil analisa penelitian menggunakan uji statistik Uji Chi-square. Syarat uji chisquare terpenuhi karena tidak ada nilai expectedcount kurang dari 5 masimal $20 \%$ dari jumlah sel. Didapatkan nilai $\rho$-value $=0,000(\rho$-value $<0,05)$ maka secara statistik ada hubungan yang signifikan antara menarche dengan dismenore primer pada siswi kelas X di SMAN 15 Semarang.

Tabel 3: Hubungan Kebiasaan Olahraga dengan nyeri Dismenore primer pada siswi di SMA Negeri 15 Semarang

\begin{tabular}{llllll}
\hline Kebiasaan Olahraga & \multicolumn{4}{c}{ Dismenore Primer } & \multicolumn{2}{l}{$\begin{array}{l}\text { Jumlah \% } \\
\text { Nilai } p\end{array}$} & Nilai p \\
\cline { 2 - 4 } & $\begin{array}{l}\text { Tidak } \\
\text { Dismenore }\end{array}$ & Nyeri Ringan & $\begin{array}{l}\text { Nyeri } \\
\text { Sedang/berat }\end{array}$ & \\
\hline $\begin{array}{l}\text { Olaraga ringan } \\
\begin{array}{l}\text { Olahraga } \\
\text { sedang/berat }\end{array}\end{array}$ & $8(5,8 \%)$ & $41(29,7 \%)$ & $42(30,4 \%)$ & $91(65,9 \%)$ & $<0,001$ \\
\hline Total & $16(11,6 \%)$ & $22(15,9 \%)$ & $9(6,5 \%)$ & $47(34,1 \%)$ & \\
\hline
\end{tabular}


Hasil uji statistik Uji Chi-square didapatkan nilai $\rho$-value $=0,000(\rho$-value $<0,05)$ maka secara statistik ada hubungan yang signifikan antara kebiasaan olahraga dengan dismenore primer pada siswi kelas X di SMAN 15 Semarang.

Tabel 4: Hubungan Stres dengan nyeri Dismenore primer pada siswi di SMA Negeri 15 Semarang

\begin{tabular}{|c|c|c|c|c|}
\hline \multirow[t]{2}{*}{ Stres } & \multicolumn{3}{|c|}{ Dismenore Primer } & \multirow[t]{2}{*}{ Jumlah \% $\quad$ Nilai $p$} \\
\hline & $\begin{array}{l}\text { Tidak } \\
\text { dismenore }\end{array}$ & $\begin{array}{l}\text { Nyeri } \\
\text { ringan }\end{array}$ & $\begin{array}{l}\text { Nyeri } \\
\text { sedang/berat }\end{array}$ & \\
\hline Normal & $15(10,9 \%)$ & $8(5,8 \%)$ & $1(0,7 \%)$ & $24(17,4)<0,001$ \\
\hline Stres ringan & $4(2,9 \%)$ & $16(11,6 \%)$ & $15(10,9 \%)$ & $35(25,4)$ \\
\hline Stres sedang & $5(3,6 \%)$ & $35(25,4 \%)$ & $8(5,8 \%)$ & $48(34,8)$ \\
\hline Stres berat/sangat berat & $0(0,0 \%)$ & $4(2,9 \%)$ & $27(19,6 \%)$ & $31(22,5)$ \\
\hline Total & $24(17,4 \%)$ & 63 (45,7\%) & $51(37,0 \%)$ & $138(100,0)$ \\
\hline
\end{tabular}

Hasil uji statistik Uji Chi-square didapatkan nilai $\rho$-value $<0,001(\rho$-value $<0,05)$ maka secara statistik ada hubunngan yang signifikan antara stres dengan dengan dismenore primer pada siswi kelas X di SMAN 15 Semarang.

\section{PEMBAHASAN}

\section{Hubungan Menarche dengan nyeri Dismenore primer}

Sesuai dengan teori yang menyatakan bahwa, bila menarche terjadi pada usia yang lebih awal dari normal, dimana alat reproduksi belum siap untuk mengalami perubahan dan masih terjadi penyempitan pada leher rahim, maka akan timbul rasa sakit ketika menstruasi. ${ }^{12}$

Hasil analisis juga diperkuat dengan penelitian terdahulu oleh Purba dkk (2013) pada siswi SMK Negeri 10 Medan, didapatkan hasil bahwa terdapat hubungan yang bermakna antara usia menarche dengan dismenore, dengan nilai $p$ sebesar $0,031(p<0,05)$. Begitupun dengan hasil penelitian Soesilowati yang menumukan ada $62,7 \%$ siswi yang mengalami dismenore dengan usia menarche dini $\leq 11$ tahun. Dapat disimpulkan bahawa usia menarche $\leq 11$ tahun memiliki resiko sebesar 3,360 kali terhadap kejadian dismenore primer pada siswi MTS, dengan nilai signifikasi hubungan $(\mathrm{p}=0.002) .{ }^{13,14}$

Hasil penelitian, menunjukkan ada 6 responden yang mendapatkaan menarche pada usia $>12$ tahun-16 tahun dan juga mengalami dismenore dengan 'nyeri berat. Biasanya menarche rata-rata terjadi pada usia 12-16 tahun. Namun dalam dasawarsa terakhir ini, usia menarche telah bergeser ke usia yang lebih muda. Usia untuk mencapai menarche dipengaruhi oleh banyak faktor antara lain suku, genetik, gizi, sosial, ekonomi dan lain-lain. ${ }^{15-17}$ 
Hasil penelitian juga menunjukkan ada 3 responden yang mendapatkan menarche pada usia < 12 tahun dan tidak mengalami dismenore. Hal ini menunjukan dismenore tidak hanya dipengaruhi oleh satu faktor saja namun banyak faktor yang saling berkaitan sehingga dapat menimbulkan nyeri menstruasi atau dismenore diantaranya, silkus menstruasi ovulatorik, lama menstruasi, riwayat ibu atau saudara kandung yang mengalami dismenore, adanya depresi atau ansietas, merokok, minum alkohol, olahraga dan faktor psikologi. ${ }^{12,18,19}$

\section{Hubungan Kebiasaan Olahraga dengan nyeri Dismenore primer}

Hasil penelitian sesuai dengan teori yang menyatakan, seseorang yang melakukan olahraga secara rutin tubuhnya akan memproduksi hormon endorphin. Endorpin merupakan suatu neuropeptid, terdapat 3 macam yakni endorphin alfa, beta, dan gamma yang semuanya dapat berikatan dengan resptor opioid dalam otak dan aktivitas analgesiknya sangat kuat. Endorpin beta terdapat dalam adenohipofisis, hipotalamus dan salah satu fungsinya berupa mediasi persepsi nyeri. 20

Hasil penelitian juga diperkuat dengan penelitian menunjukan ada hubungan kejadian dismenore dengan kebiasaan berolahraga dimana hasil analisa data dengan menggunakan metode uji Chi Square menunjukkan kejadian dismenore secara signifikan pada responden yang tidak berolahraga $(p=0,006)$. Juga sejalan dengan penelitian Sirait (2014) menunjukan hasil analisis statistik dengan menggunakan uji chi-square diperoleh nilai $p=0,040$ yang berarti terdapat hubungan yang bermakna antara kebiasaan olahraga dengan kejadian dismenore. ${ }^{20,21}$

Hasil penelitian juga menunjukan bahwa masih terdapat 9 responden yang memiliki kebiasaan olahraga sedang/berat namun masih mengalami nyeri yang sedang/berat. Hal ini dikarenakan dismenore tidak hanya desebabkan oleh satu faktor saja namun ada keterkaitan antara faktor-faktor yang lain diantaranya silkus menstruasi ovulatorik, riwayat ibu atau saudara kandung yang mengalami dismenore, adanya depresi atau ansietas, merokok, minum alkohol, olahraga dan faktor psikologi. ${ }^{12,18,19}$

\section{Hubungan Stres dengan nyeri Dismenore primer}

Hasil penelitian sesuai dengan pernyataan Hendrik (2006) \& Wangsa (2010) bahwa saat seseorang mengalami stres terjadi respon neuroendokrin sehingga $C R H$ menstimulasi sekresi $A C T H$ yang akan meningkatkan sekresi kortisoladrenal. Hormon-hormon tersebut menyebabkan sekresi $F S H$ dan $L H$ terhambat sehingga sintesis dan pelepasan progesteron terganggu. Kadar progesteron yangrendah meningkatkan sintesis prostaglandin sehingga terjadi peningkatan aktivasi PGF2á yang menyebabkan dismenorea. ${ }^{22}$

Hasil penelitian juga diperkuat dengan penelitian yang dilakukan oleh Meilina (2011) dalam Ismail, yang menunjukkan ada hubungan yang positif dan signifikan antara stres dengan kejadian dismenorea dengan nilaip $=0,000<0,05 .{ }^{1}$ Selain itu penelitian yang dilakukan oleh Priyanti (2015) juga menunjukkan ada hubungan 
tingkat stres dengan dengan terjadinya dismenore pada remaja putri di Madrasa Aliyah Mamba'ul Ulum Awang-awang Mojosari Kab. Mojokerto. ${ }^{23}$

Menurut Hawari (2008) stres dapat mengganggu kerja sistem endokrin sehingga dapat menyebabkan menstruasi yang tidak teratur dan rasa sakit saat menstruasi atau dismenorea. Wiknjosastro (2007) selain itu faktor psikis sangat berpengaruh terhadap dismenorea karena nyeri dapat dibangkitkan atau diperberat oleh keadaan psikis penderita misalnya stress. ${ }^{24}$

Hasil penelitian menunjukan bahwa terdapat 1 responden yang tidak mengalami stres/normal dan juga mengalami dismenore dengan nyeri bsedang/berat. Hal ini menunjukan bahwa dismenore tidak hanya disebabkan oleh satu faktor saja tetapi banyak faktor dan saling berkaitan yang menjadi penyebab dari terjadinya nyeri dismenore, diantaranya silkus menstruasi ovulatorik, riwayat ibu atau saudara kandung yang mengalami dismenore, adanya depresi atau ansietas, merokok, minum alkohol, olahraga dan faktor psikologi. ${ }^{12,18,19}$

\section{SIMPULAN DAN SARAN}

Ada hubungan antara menarche, kebiasaan olahraga, dan stres dengan nyeri dismenore primer pada siswi di SMAN 15 Semarang. Adapun saran penelitian yaitu diharapkan para remaja untuk meningkatkan aktifitas olahraga dan menghindari stress dengan memberikan motivasi dan dukungan, misalakan dengan menyapaikan kepada para siswa berusaha menyukai dan senang dengan pelajaran, tidak merasa terbebani dengan berbagai kegiatan disekolah dan melalukan aktifitas yang penting saja dan yang mereka mampu lakukan sehingga dapat meminimalisir/mengurangi nyeri dismenore.

\section{UCAPAN TERIMA KASIH}

Terima kasih kepada kepala SMAN 15 Semarang yang telah memberikan izin sehingga penelitian ini bisa dilakukan.

\section{DAFTAR PUSTAKA}

1. Ismail FI, Kundre R, Lolong J. Hubungan Tingkat Stres dengan Kejadian Dismenore pada Mahasiswa Semester VIII Program Studi IImu Keperawatan Fakultas Kedokteran Universitas Sam Ratulangi Manado. Ejournal Keperawatan E-Kp. 2015;3(2):1-9.

2. Latthe $P$, Mignini L, Gray R, Hills $R$, Khan K. Factors predisposing women to chronic pelvic pain: Systematic review. Br Med J. 2006;332(7544):749-51.

3. Ningsih R, Setyowati S, Rahmah H. Efektivitas Paket Pereda Nyeri Pada Remaja Dengan Dismenore. J Keperawatan Indones. 2013;16(2):67-76.

4. Ammar UR. Faktor Risiko Dismenore Primer pada Wanita Usia Subur di Kelurahan Ploso Kecamatan Tambaksari Surabaya. J Berk Epidemiol. 2016;4(1):37-49.

5. Kristianingsih A, Utami VW, Yanti DE. Resiko Dismenore Primer pada Siswi Sekolah Mengengah Pertama (SMP) Yayasan Badrul Latif (YBL) Kecamatan Natar Kabupaten Lampung Selatan. J Dunia Kesmas. 2015;4(3):175-81.

6. Rahma MA, R.D YL, Hidayati R. Hubungan antara Tingkat Stres dengan Derajat Dismenore pada Siswi SMA Negeri 1 Surakarta. Nexus Kedokt Komunitas. 2014;3(2):191-9.

7. Angelia LM, Sitorus RJ, Etrawati F. Model Prediksi Kejadian Dismenore Primer pada Siswa SMA Negeri di Palembang. J Ilmu Kesehat Masy. 2017;8(1):10-8. 
8. Bahri AA, Afriwardi, Yusrawati. Hubungan antara Kebiasaan Olahraga dengan Dismenore pada Mahasiswi Pre-Klinik Program Studi Pendidikan Dokter Fakultas Kedokteran Universitas Andalas Tahun Ajaran 2012 - 2013. J Kesehat Andalas. 2015;4(3):815-21.

9. Daley AJ. Exercise and primary dysmenorrhoea: a comprehensive and critical review of the literature. Sports Med. 2008;38(8):659-70.

10. Sari D, Nurdin AE, Defrin. Hubungan Stres dengan Kejadian Dismenore Primer pada Mahasiswi Pendidikan Dokter Fakultas Kedokteran Universitas Andalas. J Kesehat Andalas. 2015;4(2):567-70.

11. Kurniawati D, Kusumawati Y. Pengaruh Dismenore terhadap Aktivitas pada Siswi SMK. J Kesehat Masy. 2011;6(2):93-9.

12. Novia I, Puspitasari N. Faktor Risiko yang Mempengaruhi Kejadian Dismenore Primer. Indones J Public Health. 2008;4(2):96-104.

13. Purba FS, Muda S, Jamedi. Faktor-Faktor yang Berhubungan dengan Dismenore pada Siswa SMK Negeri 10 Medan Tahun 2013. J Gizi Kesehat Reproduksi Dan Epidemiol. 2013;2(5):1-10.

14. Soesilowati R, Yunia A. Pengaruh Usia Menarche terhadap Terjadinya Dismenore Primer Pada Siswi MTS Maarif NU AL Hidayah Banyumas. J IImu-IImu Kesehat. 2016;14(3):814.

15. Prawirohardjo S. Ilmu Kandungan. Jakarta: PT. Bina Pustaka; 2008.

16. Herawati R. Faktor-Faktor yang Berhubungan dengan Usia Menarche pada Remaja Putri di SMP Negeri 8 Tambusai Utara Tahun 2013. J Matern Neonatal. 2013;1(3):131-41.

17. Mutasya FU, Hasyim H. Faktor-Faktor yang Berhubungan dengan Usia Menarche Siswi SMP Adabiah. J Kesehat Andalas. 2016;5(1):233-7.

18. Hillard PJA, Deitch HR. Menstrual Disorders in the College Age Female. Pediatr Clin North Am. 2005;52:179-97.

19. Cunningham FG. OBSTETRI WILLIAMS. Jakarta: EGC; 2008.

20. Sirat DSO, Hiswani, Jemandi. Faktor-faktor yang Berhubungan dengan Kejadian Dismenore pada Siswa SMA Negeri 2 Medan Tahun 2014. J Gizi Kesehat Reproduksi Dan Epidemiol. 2014;1(4):1-10.

21. Safitri R, Rahman N, Hasanah. Hubungan Asupan Kalsium dan Aktivitas Olahraga dengan Kejadian Dismenore pada Siswa Kelas XI di SMA Negeri 2 Palu. J Kesehat Tadulako. 2015;1(1):58-669.

22. Wangsa T. Menghadapi Stress Dan Depresi. Yogyakarta: PT Suka Buku; 2010.

23. Priyanti S, Mustikasari AD. Hubungan Tingkat Stres Terhadap Dismenore Pada Remaja Putri Di Madrasah Aliyah Mamba' UI Ulum Awang-Awang Mojosari Mojokerto. J Hosp Majapahit. 2014;6(2):1-10.

24. Hawari. Manajemen Stres. Jakarta: Nuha Medika; 2010. 